Proc. Estonian Acad. Sci. Eng., 2006, 12, 4, 358-367

\title{
Thermophysical properties and thermal shock resistance of chromium carbide based cermets
}

\begin{abstract}
Maksim Antonov and Irina Hussainova
Department of Materials Engineering, Tallinn University of Technology, Ehitajate tee 5, 19086 Tallinn, Estonia; Maksim.Antonov@ttu.ee, irhus@staff.ttu.ee

Received 2 June 2006

Abstract. Particle-reinforced ceramic metal composites (cermets) have attracted considerable attention for use in industry in situations when corrosive and aggressive wear resistance is needed. The aim of this work is to explore thermal conductivity and thermal expansion of the cermets at temperatures up to $1200^{\circ} \mathrm{C}$. The effects of microstructure and thermal properties of the constituents $\left(\mathrm{Cr}_{3} \mathrm{C}_{2}\right.$ and $\left.\mathrm{Ni}\right)$ on the resulting properties of the cermet are studied. Different mathematical models and their validity for multiphase materials are presented. Thermal shock resistance is evaluated. Analytical results are compared with experimental data. On the basis of presented models an analysis of the properties of interfaces between carbide grains and/or grains and matrix metal is carried out.
\end{abstract}

Key words: thermophysical properties, thermal shock, cermets, models.

\author{
Nomenclature: \\ $\alpha$ - coefficient of thermal expansion \\ $\lambda$ - thermal conductivity \\ $h$ - conductance of the interface barrier between \\ filler and matrix \\ $a$ - thermal diffusivity \\ $c_{p}$ - specific heat \\ $E$ - Modulus of elasticity \\ $K$ - bulk modulus
}

$$
\begin{aligned}
& G \text { - shear modulus } \\
& V \text { - volume fraction } \\
& v \text { - Poisson ratio } \\
& \sigma \text { - transverse rupture strength } \\
& \rho \text { - density } \\
& \text { Subscripts: } \\
& c \text { - composite } \\
& m \text { - matrix (metal) } \\
& f \text { - filler (carbide) }
\end{aligned}
$$

\section{INTRODUCTION}

In the process of manufacturing more efficient gas turbines and engines and their components for many applications at elevated temperatures, much effort has been directed to the development of refractory materials. Among new materials, 
particle-reinforced ceramic metal composites (cermets and hard metals) have attracted considerable attention. Chromium carbide based cermets are materials that have a leading position in applications where chemical stability for the temperature approaching $1300^{\circ} \mathrm{C}$ is highly important.

In this paper, to predict material behaviour at elevated temperatures, thermophysical properties and thermal shock resistance have been investigated. As such properties, thermal expansion and thermal conductivity were chosen due to their importance in the process of generating thermal gradients and thermal stresses inside composites that in its turn has an effect on thermal stress resistance and overall performance of materials at high temperatures. Different mathematical models for the prediction of thermal conductivity and expansion of composites on the basis of the properties of constituents $\left(\mathrm{Cr}_{3} \mathrm{C}_{2}\right.$ and $\left.\mathrm{Ni}\right)$ and their compositions (arrangements) were tested and their validity discussed. These models allow an analysis of the properties of interfaces and to obtain useful information about the contacts between carbide grains.

\section{MATERIALS}

Three grades of $\mathrm{Cr}_{3} \mathrm{C}_{2}$-Ni cermets were fabricated at Tallinn University of Technology from $\mathrm{Cr}_{3} \mathrm{C}_{2}$ and Ni powders using a conventional powder metallurgy technique. The working sides of specimens were polished with $3 \mu \mathrm{m}$ diamond paste. The matrix content was chosen as 8,16 and $33 \mathrm{vol} \%$ (10, 20 and $40 \mathrm{wt} \%$, respectively) to provide a difference in terms of contacts between carbide grains. SEM micrographs of cermets with 8 and 33 vol\% are presented in Fig. 1. Porosity was about $1 \%$ for all materials tested and carbide grain size was in the range of $2-5 \mu \mathrm{m}$.

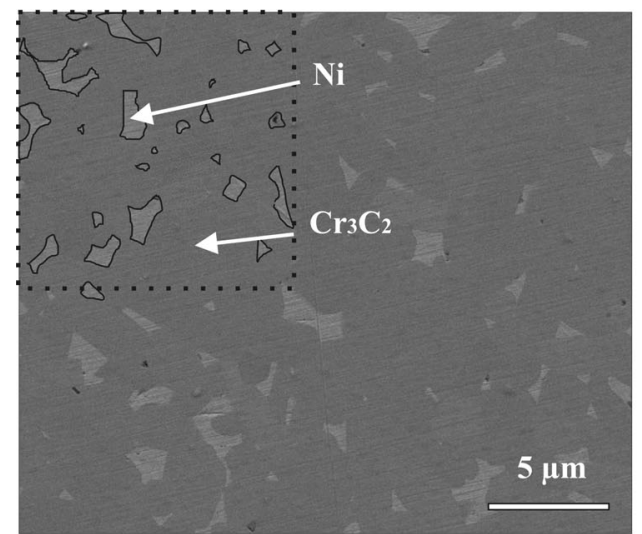

(a)

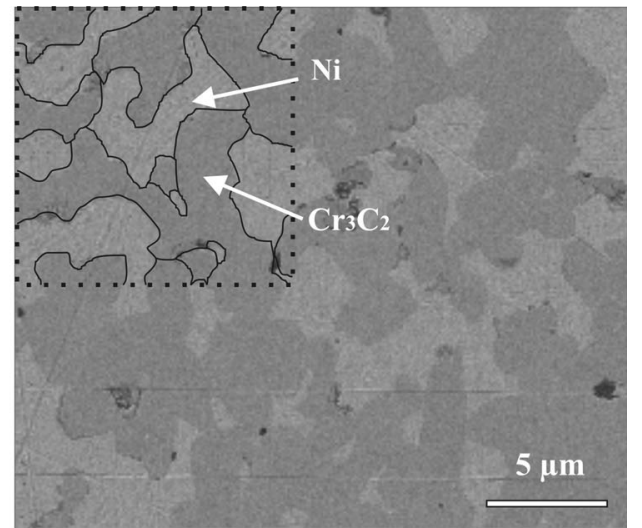

(b)

Fig. 1. SEM micrographs of chromium carbide cermets: (a) $\mathrm{Cr}_{3} \mathrm{C}_{2}-8$ vol\% Ni; (b) $\mathrm{Cr}_{3} \mathrm{C}_{2}-33$ vol\% Ni. 
Table 1. Physical and mechanical properties of chromium carbide and nickel

\begin{tabular}{|c|c|c|c|c|c|c|c|c|}
\hline 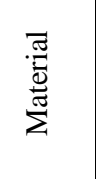 & 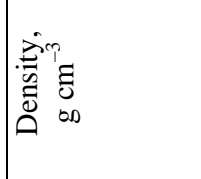 & 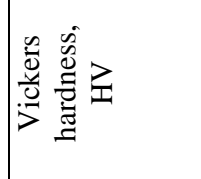 & 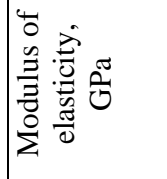 & 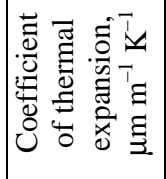 & 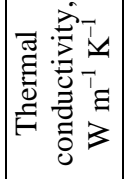 & Dี & 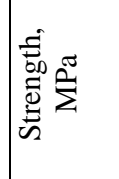 & 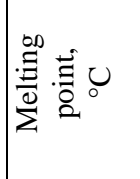 \\
\hline $\mathrm{Ni}$ & $8.88\left[^{2}\right]$ & $\begin{array}{l}75\left[^{2}\right] \\
\text { (annealed) }\end{array}$ & $207\left[{ }^{2}\right]$ & $\begin{array}{l}13.1\left[^{2}\right]^{*} \\
13.4\left[^{3}\right] \\
13.3\left[^{4}\right] \\
\left(20^{\circ} \mathrm{C}\right)\end{array}$ & $\begin{array}{l}94\left[^{3}\right]^{*} \\
\left(0^{\circ} \mathrm{C}\right) \\
60.7\left[^{2}\right] \\
90\left[^{4}\right]\end{array}$ & & $\begin{array}{l}59\left[^{2}\right] \\
\text { (yield } \\
\text { strength } \\
\text { in } \\
\text { tension) }\end{array}$ & $1455\left[^{2}\right]$ \\
\hline $\mathrm{Cr}_{3} \mathrm{C}_{2}$ & $\begin{array}{l}6.66-6.68\left[^{2}\right]^{*} \\
6.68\left[^{1}\right] \\
6.70\left[^{6}\right]\end{array}$ & $\begin{array}{l}1081-2101\left[^{5}\right]^{*} \\
1020-1835\left[{ }^{1}\right] \\
1870\left[{ }^{6}\right]\end{array}$ & $\begin{array}{l}380\left[\left[^{5}\right]^{*}\right. \\
344-400\left[{ }^{1}\right] \\
373-386\left[{ }^{2}\right]\end{array}$ & $\begin{array}{l}10.3\left[^{2}\right]^{*} \\
10.4\left[^{1}\right] \\
\left(20^{\circ} \mathrm{C}\right)\end{array}$ & $\begin{array}{l}19\left[^{1}\right] \\
\left(20^{\circ} \mathrm{C}\right)\end{array}$ & $0.20 * *$ & $\begin{array}{l}1039\left[^{2}\right] \\
\text { (yeld } \\
\text { strength } \\
\text { in } \\
\text { compre- } \\
\text { ssion) }\end{array}$ & $\begin{array}{l}1800\left[{ }^{2}\right]^{*} \\
1810\left[{ }^{1}\right]\end{array}$ \\
\hline
\end{tabular}

\footnotetext{
* The mean value was chosen for calculations throughout the article.

** Typical value for carbides of metals of the transition group VIB $\left.{ }^{1,2}\right]$.
}

In Fig. 1, ceramic-metal interfaces are shown by black lines. Carbide grains in the cermet with high binder content (33 vol\%) are mostly isolated from each other by the matrix while grains develop a carbide skeleton in the cermet with low binder content ( 8 and 16 vol\%). The carbide-binder contact area is less in materials with lower binder content. Cermets with low content of the binder metal may be classified as ceramic matrix composites.

Physical and mechanical properties of chromium carbide and nickel are listed in Table 1. Modulus of elasticity of $\mathrm{Ni}$ is almost a half of that of $\mathrm{Cr}_{3} \mathrm{C}_{2}$. Coefficients of thermal expansion and thermal conductivity are higher in the metal matrix as compared to carbide grains. Hardness of the chromium carbide is high and differs lightly from the hardness of tungsten carbide $\left(\mathrm{HV}=2243\left[^{1}\right]\right)$ explaining high potential of these materials in applications where wear resistance is important.

\section{THERMOPHYSICAL PROPERTIES}

\subsection{Thermal expansion}

One of the most important parameters in the generation of thermal stresses is the coefficient of thermal expansion (CTE) or, to be more precise, the difference in CTE for two or more phases. Residual thermal stresses are created during the cooling of the material, after sintering. Nickel has higher thermal expansion than the carbides (Table 1) and therefore the ceramic particles are in compression assuring better performance under mechanical loading. 
Coefficient of thermal expansion of cermets was determined with the dilatometer DIL 402 (Netzsch). Effect of the temperature and composition on the CTE of pure $\mathrm{Ni}$ and chromium carbide cermets is shown in Fig. $2 \mathrm{a}\left[{ }^{3}\right]$. Generally, cermets with higher binder content exhibit higher CTE than cermets with lower binder content.

Thermal expansion of cermets is relatively stable in the temperature range from 150 to $1050^{\circ} \mathrm{C}$. At temperatures below $150^{\circ} \mathrm{C}$, CTE is slightly higher as compared to the temperature of transition to the stable region. This can be explained by residual stresses, created in the chromium carbide. Temperature change over $100^{\circ} \mathrm{C}$ during cooling is able to create tensile stresses in $\mathrm{Ni}$ that exceed its yield strength of $59 \mathrm{MPa}$ (Table 1) $\left[{ }^{4}\right]$. Lowering of CTE at temperatures above $1050^{\circ} \mathrm{C}$ can be attributed to the partial evaporation or softening of the metal component at these temperatures.

Widely used models for the prediction of CTE $\left[{ }^{7-9}\right]$ are presented in Table 2. The classical rule-of-mixture model describes the CTE in the direction, normal to the set of layers of the matrix and filler (multilayer model). Turner's model describes the behaviour of particulate reinforced composites, considering uniform hydrostatic stresses. Kerner's model is proposed for the composite consisting of spherical particles dispersed in the matrix. Figure $2 \mathrm{~b}$ represents analytical and experimental results on the dependence of CTE on the ceramic phase content. It confirms relatively good agreement of all models with experimental results. In general, the chromium carbide based cermet can be treated as a particulate reinforced as well as a multilayer material. The CTE of cermets with lower binder content is overestimated that can be explained by the formation of the continuous carbide skeleton and by the inability of the Ni binder to deform it.

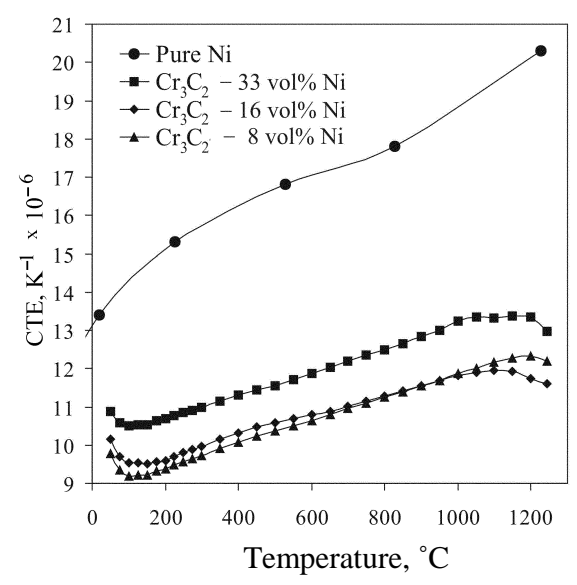

(a)

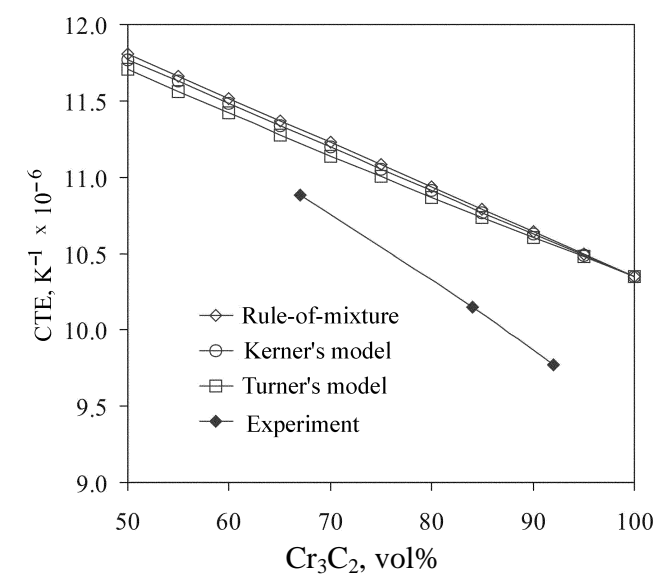

(b)

Fig. 2. Effect of the temperature (a) and ceramic phase content (b) on CTE of pure nickel and chromium carbide based cermets (at room temperature). 
Table 2. Models for prediction of CTE of composites

\begin{tabular}{cl}
\hline Name of the model & \multicolumn{1}{c}{ Model } \\
\hline $\begin{array}{l}\text { Rule-of-mixture } \\
\text { Turner's model }\end{array}$ & $\begin{aligned} \alpha_{c} & =\alpha_{m} V_{m}+\alpha_{f} V_{f} \\
\alpha_{c} & =\frac{\alpha_{m} K_{m} V_{m}+\alpha_{f} K_{f} V_{f}}{K_{m} V_{m}+K_{f} V_{f}} \\
K & =\frac{E}{3(1-2 v)} \\
\text { Kerner's model } & \alpha_{c}=\alpha_{m} V_{m}+\alpha_{f} V_{f}+V_{f} V_{m}\left(\alpha_{f}-\alpha_{m}\right) \times \frac{K_{f}-K_{m}}{V_{m} K_{m}+V_{f} K_{f}+\left(3 K_{f} K_{m} / 4 G_{m}\right)} \\
& G=\frac{E}{2(1+v)}\end{aligned}$
\end{tabular}

\subsection{Thermal conductivity}

Cermets consist of phases with different heat transport mechanisms. Through ceramic carbide particles heat is transported by phonons while metal matrix involves electrons for heat conductivity. Boundaries between these two phases play an important role because of the change of the heat carriers. The coefficient of thermal diffusivity $(a)$ and specific heat $\left(c_{p}\right)$ were used to determine the coefficient of thermal conductivity $(\lambda): \lambda=c_{p} a \rho$, where $\rho$ is the material density. In order to determine the thermal conductivity with a great accuracy in the temperature range from the room temperature to $1500^{\circ} \mathrm{C}$, the diffusivity was measured with a laser flash apparatus combined with an IR sensor by the differential scanning calorimetric method. Effect of the temperature on the thermal conductivity of pure nickel $\left[{ }^{3,10}\right]$ and cermets are presented in Fig. $3 a$.

Conductivity of composites is lower than that of ceramic and metallic constituents. Grain boundaries promote scattering and reduce thermal conductivity of cermets. The effect of scattering at boundaries is high for cermets with low binder content and refined structure. Presence of pores induces convective or radiate heat transport across individual pores and additional lowering of the heat transfer rate.

Widely used models $\left[{ }^{10-12}\right]$ for the prediction of thermal conductivity are listed in Table 3. Maxwell's model describes the behaviour of composites consisting of the matrix and randomly distributed and randomly sized spherical particles. Interface conductance $(h)$ was introduced in the Hasselman-JohnsonBenveniste (HJB) model. The Cube model (proposed by the authors) considers the cermets as a set of square columns, some of which consist of metal and ceramic phases and others consist only of the metal phase. Columns that have metal-ceramic interfaces are taken as non-conductive.

The effect of the binder on thermal conductivity of composites at room temperature is presented in Fig. 3b. Importance of interface layers is clearly seen. The models that do not take them into account overestimate the value of $\lambda$. The 


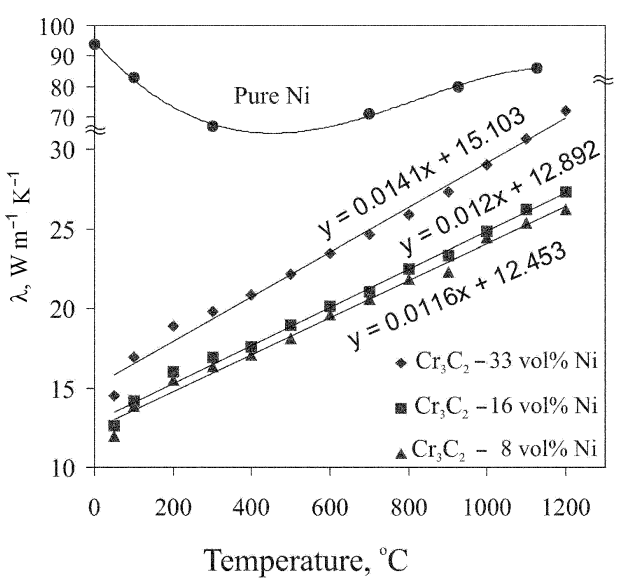

(a)

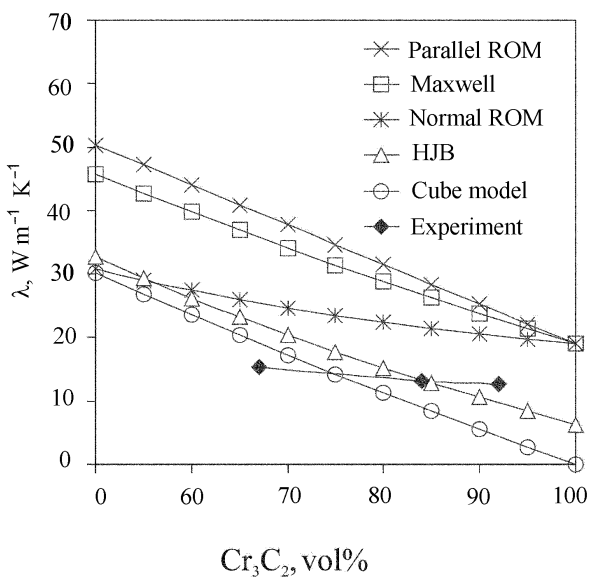

(b)

Fig. 3. (a) Dependence of the coefficient of thermal conductivity of pure nickel and chromium carbide cermets on the temperature; (b) dependence of the coefficient of thermal conductivity of cermets at room temperature on the content of the ceramic phase.

Table 3. Models for the prediction of the coefficient of thermal conductivity of composites

\begin{tabular}{l|l}
\hline \multicolumn{1}{c|}{ Name of the model } & \multicolumn{1}{c}{ Model } \\
\hline $\begin{array}{l}\text { Rule-of-mixture for heat flow parallel } \\
\text { to layers (parallel ROM) }\end{array}$ & $\lambda_{c}=\lambda_{m} V_{m}+\lambda_{f} V_{f}$ \\
$\begin{array}{l}\text { Rule-of-mixture for heat flow normal } \\
\text { to layers (normal ROM) }\end{array}$ & $\lambda_{c}=\frac{\lambda_{m} \lambda_{f}}{\lambda_{m} V_{f}+\lambda_{f} V_{m}}$ \\
Maxwell's model & $\lambda_{c}=\frac{2\left(1-V_{f}\right)+\lambda_{f}\left(1+2 V_{f}\right)}{\left(2+V_{f}\right)+\lambda_{f}\left(1-V_{f}\right)}$ \\
$\begin{array}{l}\text { Hasselman-Johnson-Benveniste } \\
\text { (HJB) model }\end{array}$ & $\lambda_{c}=\frac{\left(2-2 V_{f}\right)+h\left\{\frac{1+2 V_{f}+\left(2-2 V_{f}\right)}{\lambda_{f} / \lambda_{m}}\right\}}{\left(2+2 V_{f}\right)+h\left\{\frac{1-2 V_{f}+\left(2+2 V_{f}\right)}{\lambda_{f} / \lambda_{m}}\right\}}$
\end{tabular}

Cube model

$$
\lambda_{c}=\left(1-V_{f}^{\frac{2}{3}}\right) \lambda_{f}
$$

conductance of interfaces in the HJB model can vary from 0 to $10\left[^{12}\right]$. The model fits experimental results with the interface conductance values of 0.42 , 0.26 (as was taken by the construction of Fig. 3b) and 0.001 for cermets with 8 , 16 and $33 \mathrm{vol} \%$ of $\mathrm{Ni}$, respectively. Those values indicate that the interface conductance between $\mathrm{Cr}_{3} \mathrm{C}_{2}$ and $\mathrm{Ni}$ is extremely low. The cube model seems to be suitable for the prediction of thermal conductivity of the ceramic-metal composite. 


\section{THERMAL SHOCK PROPERTIES}

Materials that are used in high-temperature applications are often exposed to rapid temperature changes, which cause thermal stresses and creates the risk of thermal shock damage. A commonly used empirical parameter to evaluate tool materials for their probable resistance to thermal shock is $(\sigma \lambda) /(E \alpha)\left[{ }^{13}\right]$. In contrast to conventional WC-Co cermets, $\mathrm{Cr}_{3} \mathrm{C}_{2}$-based cermets have comparatively lower resistance to thermal shock.

Different methods are applied for the evaluation of thermal shock properties of brittle materials and cermets. Most of the methods are based on the measuring of the number and the length of cracks and mechanical properties after the thermal shock test, while the others take into consideration the initial cracks in the materials $\left[{ }^{14-16}\right]$.

To evaluate the effect of thermal processes on crack formation and propagation, cermets were thermally shocked. Test samples were heated up to 1200 or $800^{\circ} \mathrm{C}$ with heating speed of $400^{\circ} \mathrm{C} / \mathrm{min}$ and cooled in water or air. Tests were repeated until complete fracture of the material.

With the help of high-resolution optical and SEM micrographs it was found that the extension of thermally induced cracks in the material with low binder content is larger than that in the materials with the high one. It was also found that cermets with 8 and 16 vol\% of the matrix had higher weight gain during the thermal cycling that could be explained by the higher extent of cracks, which are additional areas for rapid oxidation. The effect of higher thermal expansion of materials, possessing high binder content, is supposed to be compensated by their higher thermal conductivity, i.e. by the ability to avoid high thermal gradients. No notable differences in materials behaviour were found during the tests, carried out with different heating temperatures $\left(800\right.$ and $\left.1200{ }^{\circ} \mathrm{C}\right)$. The cracks, crossing the whole specimen, were found after the very first thermal shock. Cracking of large carbide grains was found in all materials tested. Although cracks, crossing the whole specimen, were initiated at the first cycle, the material still could withstand mechanical loads and operate as a whole; the erosion resistance of thermally shocked material was not significantly decreased. Difference in the CTE of the two phases leads to alternating stresses to be imposed in ceramic grains and metal binder and results in debonding at the metal - carbide interfaces (Fig. 4). This effect was specially promoted in the presence of large areas of the metallic phase. Despite of this, the specimens were able to sustain 650 thermal cycles (maximum number of cycles applied). Plastically deformed nickel could hold parts of the specimen together. In all cases, the propagation of several main cracks has lead to the fracture of the cermet.

Existence of the continuous metal phase makes it possible for the crack to propagate through the matrix (Fig. 4). Moreover, good fracture toughness of the metal facilitates the crack deceleration in the binder phase (Fig. 4). A dislocation pileup is formed and subsequently that induces the formation of the crack nuclei when the maximum shear stress is greater than the critical stress for dislocation 


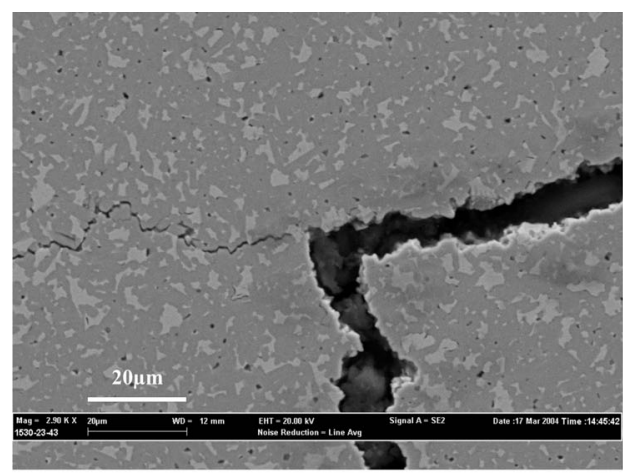

(a)

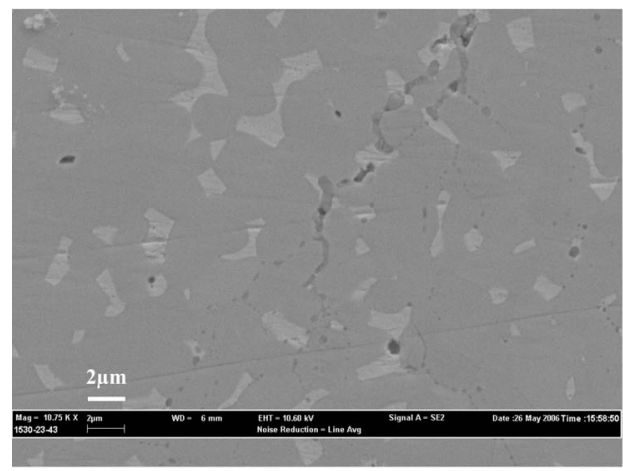

(c)

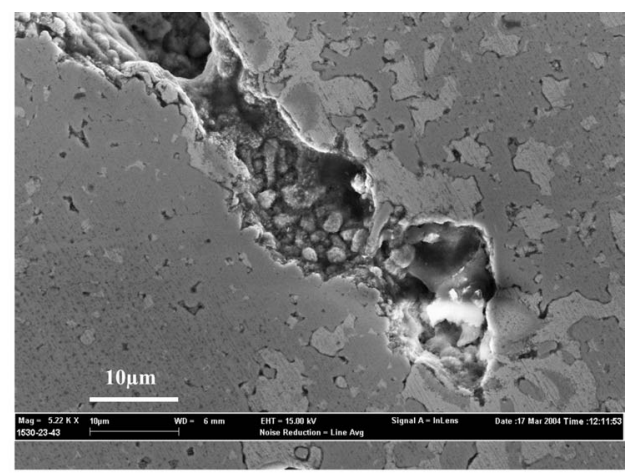

(b)

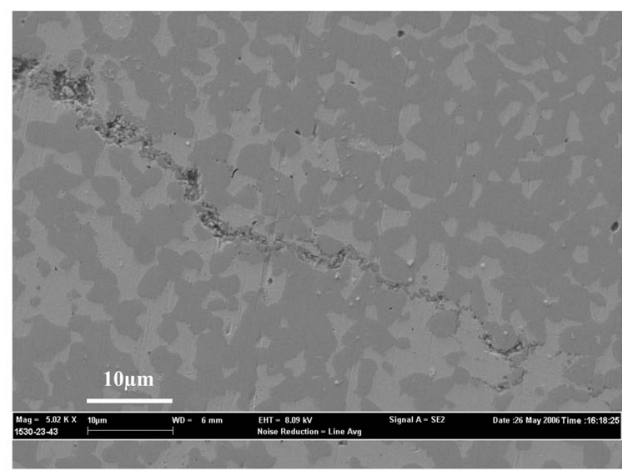

(d)

Fig. 4. SEM micrographs of thermally induced cracks in materials subjected to thermal shock tests: (a) the main crack; (b) the end of the main crack and decohesion of the binder metal from carbide particles; (c) tiny thermo-cracks; (d) damping of the thermal crack.

generation. In the cermets, containing a high volume of the ceramic phase, the interfaces is the preferred site to produce microcracks because of the presence of crystallographically disoriented boundaries and large residual stresses at those areas. Figure 4 presents the SEM micrographs of thermally induced cracks.

The thickness of the specimen was found to be the critical parameter for thermal shock resistance. Complete fracture of specimens with a thickness of $10 \mathrm{~mm}$ was observed after 3-7 cycles while the specimens with a thickness of $5 \mathrm{~mm}$ could be broken by applying bending momentum of about $5 \mathrm{Nm}$ only after 10-20 cycles.

\section{CONCLUSIONS}

The value of the coefficients of thermal conductivity and of thermal expansion of $\mathrm{Cr}_{3} \mathrm{C}_{2}$-Ni cermets with 8,16 and 33 vol\% were measured experimentally and analysed. Proposed mathematical models were compared with 
experimental results. The importance of the ceramic-metal interface conductivity for the calculation of thermal conductivity was demonstrated. Low value (lower than that of $\mathrm{Cr}_{3} \mathrm{C}_{2}$ or $\mathrm{Ni}$ phases) of thermal conductivity of cermets with low nickel content was shown to be due to the presence of interfaces between carbides.

Thermal shock experiments have shown that the extension of cracks in materials with lower binder content is slightly greater.

The thickness of the specimen was found to be the critical parameter of thermal shock resistance. It was shown that there is no big difference in the behaviour of cermet grades of different binder content at conditions of thermal shock that may be attributed to the compensating influence of CTE and thermal conductivity.

\section{ACKNOWLEDGEMENTS}

This work was supported by Estonian Science Foundation (grants Nos. 6163 and 6660), and by EC Program "Improving the Human Research Potential". The authors would like to thank the staff of Aerospace Materials Technology Testhouse in Vienna for professional help by the analysis of the samples.

\section{REFERENCES}

1. Pierson, H. Handbook of Refractory Carbides and Nitrides: Properties, Characteristics, Processing, and Applications. Noyes publications, New Jersey, 1996.

2. Searchable database of material data sheets. http://www.matweb.com/

3. Kaye, G. and Laby, T. Tables of Physical and Chemical Constants, 16th ed. Longman, London, 1995.

4. Callister, W. D. Material Science and Engineering. An Introduction, 5th ed. John Wiley, New York, 2000.

5. Upadhyaya, G. S. Nature and Properties of Refractory Carbides. Nova Science Publishers, New York, 1996.

6. Micro-Electro-Mechanical Systems and Nanotechnology. Clearinghouse. http://www.memsnet.org/

7. Shu, K.-M. and Tu, G. C. The microstructure and the thermal expansion characteristics of $\mathrm{Cu} / \mathrm{SiCp}$ composites. Mater. Sci. Eng., 2003, 349, 236-247.

8. Elomari, S., Skibo, M. D., Sundarrajan, A. and Richards, H. Thermal expansion behavior of particulate metal-matrix composites. Compos. Sci. Technol., 1998, 58, 369-376.

9. Chawla, N., Patel, B. V., Koopman, M., Chawla, K. K., Saha, R., Patterson, B. R., Fuller, E. R. and Langer, S. A. Microstructure-based simulation of thermomechanical behavior of composite materials by object-oriented finite element analysis. Mater. Charact., 2002, 49, 395-407.

10. Krishnaiah, M. V., Seenivasan, G., Srirama Murti, P. and Mathews, C. K. Thermal conductivity of selected cermet materials. J. Alloys Compounds, 2003, 353, 315-321.

11. Clyne, T. W. and Withers, P. J. An Introduction to Metal Matrix Composites. Cambridge Univ. Press, Cambridge, 1995.

12. Taya, M. and Arsenault, R. J. Metal Matrix Composites. Thermomechanical Behavior. Pergamon, London, 1989. 
13. Chandra, U. Control of Residual Stresses. ASM handbook, Vol. 20 (Materials Selection and Design). ASM International, New Jersey, 1993.

14. Aksel, C. Mechanical properties and thermal shock behaviour of alumina-mullite-zirconia and alumina-mullite refractory materials by slip casting. Ceram. Int., 2003, 29, 311-316.

15. Collin, M. and Rowcliffe, D. Analysis and prediction of thermal shock in brittle materials Acta Mater., 2000, 48, 1655-1665.

16. Ishihara, S., Goshima, T., Nakayama, I. and Yoshimoto, T. Crack growth behaviour due to repeated thermal shock in cemented carbides and cermets. In Proc. Sixth International Fatigue Congress (Lutjering, G. and Nowack, H., eds.). Berlin, 1996, 1633-1638.

\section{Kroomkarbiidkermiste termofüüsilised omadused ja püsivus termolöögil}

\section{Maksim Antonov ja Irina Hussainova}

Kroomkarbiidkermised on perspektiivsed materjalid kasutamiseks agressiivsetes ja abrasiivsetes tingimustes. Artikli eesmärgiks on uurida $\mathrm{Cr}_{3} \mathrm{C}_{2}-\mathrm{Ni}$ kermiste termilist juhtivust ja paisumist temperatuuril kuni $1200^{\circ} \mathrm{C}$. On tuletatud nende parameetrite sõltuvus kermise struktuurist ning kirjeldatud matemaatilisi mudeleid ja uuritud viimaste adekvaatsust. Nende mudelite baasil on analüüsitud karbiiditerade ning keraamilise ja metalse faasi vaheliste pindade omadusi. On määratud materjalide püsivus termolöögil. 